\title{
Crustal structure in Xiaojiang fault zone and its vicinity*
}

\author{
Chunyong Wang ${ }^{1, \star}$ Hai Lou $^{1} \quad$ Xili Wang ${ }^{1}$ \\ Jiazheng Qin ${ }^{2}$ Runhai Yang ${ }^{2}$ and Jinming Zhao ${ }^{2}$ \\ ${ }^{1}$ Institute of Geophysics, China Earthquake Administration, Beijing 100081, China \\ ${ }^{2}$ Earthquake Administration of Yunnan Province, Kunming 650224, China
}

\begin{abstract}
Based on the integrative interpretation of travel-time data and amplitude information obtained from the deep seismic sounding experiment on the Chuxiong-Luoping profile, eastern Yunnan province, carried out in January of 2005, we present a 2-D P wave velocity structure along the profile. The crustal structure shows remarkable contrasts between the two sides of the Xiaojiang fault zone, although the whole profile is situated within the Yangtze platform. The average P wave velocities of the crust on the west and east sides of the fault zone are $6.21 \mathrm{~km} / \mathrm{s}$ and $6.32 \mathrm{~km} / \mathrm{s}$, respectively, and the crustal thicknesses are $41 \mathrm{~km}$ and $45 \mathrm{~km}$, respectively. These results imply that the crust to the east of the Xiaojiang fault zone presents characteristics of crustal structure in a stable platform, while the crust to the west is complicated with a lower velocity zone in middle of the upper crust. The average velocity of $6.21 \mathrm{~km} / \mathrm{s}$ is lower than the global continental crustal average $(6.30 \mathrm{~km} / \mathrm{s})$, indicating that the region is tectonically active. According to the lateral variation of velocity and depth of interfaces (including the Moho), it is inferred that the Xiaojiang fault zone has cut through the whole crust. It is also deduced that existence of low velocity zone in middle of the upper crust is conducive to the south-southeastern sliding of the SichuanYunnan (Chuan-Dian) rhombus block.
\end{abstract}

Key words: Xiaojiang fault zone; crustal structure; deep seismic sounding; seismicity; low velocity zone CLC number: P315.3 $\quad$ Document code: A

\section{Introduction}

The Xianshuihe-Anninghe-Xiaojiang fault zone, stretching about $2000 \mathrm{~km}$, is an important tectonic zone on the eastern margin of the Tibetan plateau. It is considered as an active fault zone since the neotectonic epoch and has been frequented by strong earthquakes and severe geological disasters. On the Xianshuihe fault zone, i.e., the north segment of the tectonic zone, six earthquakes with magnitude $M>7$ occurred in the last century, such as the Kangding M7.5 earthquake in 1950 and the Luhuo M7.6 earthquake in 1979. On the Xiaojiang fault zone (XFZ), i.e., the south segment of the tectonic zone, more than ten earthquakes with magnitude $M>6$ have occurred. Among them, the strongest is the Songming M8.0 earthquake in 1833 , which is only $30 \mathrm{~km}$ away from Kunming city.

\footnotetext{
* Received 12 May 2009; accepted in revised form 30 June 2009; published 10 August 2009.

^ Corresponding author. e-mail: wangcy@cea-igp.ac.cn
}

During the last ten years, a series of moderate and strong earthquakes have occurred in Kunming and its vicinity. In the project "Exploration of Active Seismic Faults in Large Cities and Earthquake Risk Assessment" during the tenth "Five-year Plan" period proposed by China Earthquake Administration, Kunming is one of the large cities for active fault explorations. As a main part of the active fault exploration, a deep seismic sounding (DSS) experiment, named as project $\mathrm{KS} 04$, was carried out along the Chuxiong-Luoping seismic profile in January of 2005 to explore the crustal structure and deep configuration of active fault zones in Kunming and its nearby area. The profile traverses Kunming city and the XFZ. In this paper, we present a 2-D P-wave velocity structure along the profile based on the seismic records of explosions. The deep configurations of the XFZ and the Puduhe fault, as well as their possible influence on the Kunming area are also discussed. 


\section{Geological setting and previous geo- physical results}

The studied area is located at the junction of three first-order tectonic units: Yangtze platform, South China fold system and Lanping-Simao fold system (Bureau of Geology and Mineral Resources of Yunnan Province, 1990). The DSS profile crosses two second-order tectonic units, i.e., the Sichuan-Yunnan (Chuan-Dian) anticline and the eastern Yunnan fold belt, both belong to the Yangtze platform. The Kunming basin is the largest Quaternary inherited downfaulted basin in the YunnanGuizhou plateau, where the strata developed in Quaternary are characterized by large variation of thickness and complicated facies. According to the regional plate partition, the profile is situated on the boundary between the Tibetan plate (i.e., Chuan-Dian rhombus block, shortened as CDRB) and the South China plate (i.e., South China block) (Figure 1). The XFZ, totaling a length of $400 \mathrm{~km}$ in north-south trending, is the southeastern boundary of CDRB and can be divided into three segments. The north segment is from Qiaojia to Menggu; the middle is divided into eastern and western branches: the east branch starts at Menggu in the north and stretches to the southern end of Yiliang basin, and the west branch starts at Daduo in the north and extends to the south of Chengjiang; the south segment lies from the southern end of Yiliang basin near Xujiadu to the southeast of Jianshui. The Quaternary tectonic activity of the XFZ is characterized by strong sinistral strike slip. The Puduhe fault, with a length of $280 \mathrm{~km}$, is located within CDRB. It begins at the north of Jinshajiang river, extending to south along the Puduhe river through Kunming and Yuxi, and ends at the vicinity of Eshan. The Puduhe fault was intensively active during Indo-Chinese and Yanshan epochs.

As regards the seismicity, there are the Yimen and Puduhe seismic belts with moderately strong activity and the Xiaojiang seismic belt with strong activity in the studied area. Along the Yimen seismically active belt, several intermediate and strong earthquakes with magnitude 6 or greater have occurred in history. Among them, the strongest is the Wuding M6.5 earthquake in 1995. Several intermediate and strong earthquakes have also occurred on the Puduhe seismically active belt, the strongest being the Luquan M6.3 earthquake in 1985. More than ten strong earthquakes with magnitude $M>6$ have occurred along the Xiaojiang seismic belt. The strongest is the Songmin M8.0 earthquake in 1833.
Since the 1960's, much effort has been devoted to the study on XFZ and the seismic tectonics in Yunnan area. Xie (1958) was the first to associate the strong seismic activities with XFZ. Kan et al (1977) studied the modern stress field in western China in detail and presented the concept of "Chuan-Dian rhombus block". The first DSS experiment in Yunnan was carried out in 1982, which is called "Dian-Shen 82". Based on the seismic data, Yan et al (1985), Hu et al (1986), Kan et al (1986), Kan and Lin (1986) and Kan and Han (1992) expounded the crustal structure in Yunnan area. Zhou et al (2001) studied the petrological structure of the crust and upper mantle using the DSS results and other field and experimental data in Yunnan. Recently, Bai and Wang (2003, 2004) and Zhang et al (2005) reanalyzed these DSS data, respectively. Through the seismic tomography of the travel-time data from Yunnan seismic network, Liu et al (1989), Chen et al (1990) and Wang et al (1994, 2003) investigated the structure of the crust and uppermost mantle in Yunnan area, respectively. Most of these studies were concentrated on the western Yunnan area

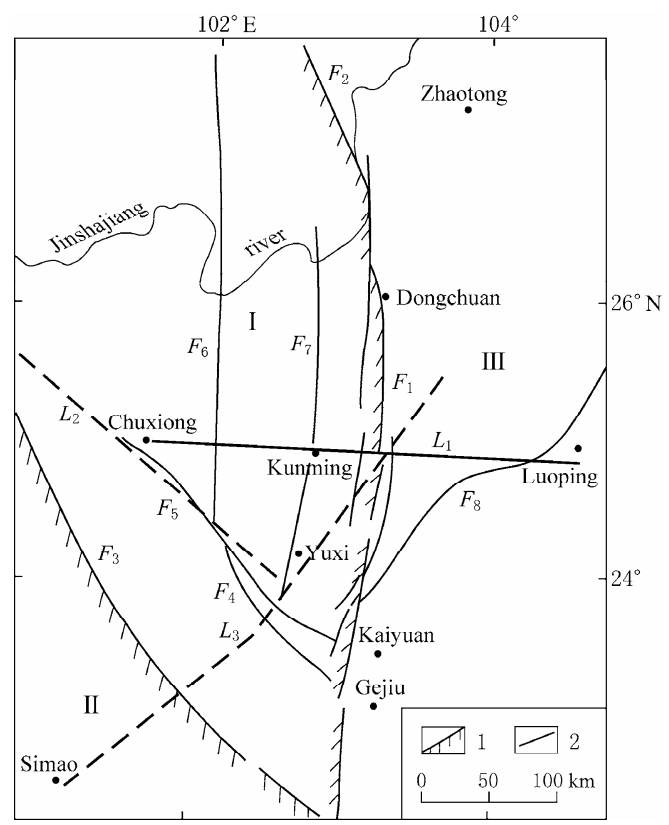

Figure 1 Regional tectonic framework (after Ma, 1989) and positions of DSS profiles. 1. Boundary fault of plate; 2. Other faults; I. Qinghai-Tibet plate (CDRB); II. Southeast Asia plate (Lincang-Simao block); III. South China plate (South China block); $F_{1}$. Xiaojiang fault; $F_{2}$. Zemuhe fault; $F_{3}$. Honghe fault; $F_{4}$. Shiping-Jianshui fault; $F_{5}$. Chuxiong-Eshan fault; $F_{6}$. Yuanmou fault; $F_{7}$. Puduhe fault; $F_{8}$. Mile fault. $L_{1}$, $L_{2}$ and $L_{3}$ denote the positions of three DSS profiles, i.e., Chuxiong-Luoping, Eryuan-Jiangchuan and Simao-Malong profiles, respectively. 
and the Honghe fault zone, while paid a little attention to the eastern Yunnan area and XFZ.

\section{Seismic data and phase analysis}

\subsection{Layout and observations}

The Chuxiong-Luoping DSS profile $(295.67 \mathrm{~km}$ in length) begins at the southern part of Chuxiong in the west, extends eastwards through the Yuanmou fault, Yimen fault, Puduhe fault, Xiaojiang fault and Mile fault, and terminates at the southern part of Luoping. The Eryuan-Jiangchuan profile and Malong-Simao profile in the "Dian-Shen 82 " experiment pass through the studied area (Figure 1). Eight shots, i.e., Chuxiong (CHX), Dahaibo (DHB), Qinglongsi (QLS), Tangchi (TCH), Zhangziba (ZZB), Luliang (LUL), Xinglongcun
(XLC) and Luoping (LUP), were fired along the profile. The explosive charge of each shot varies from $1800 \mathrm{~kg}$ to $3000 \mathrm{~kg}$, except for the shots TCH and ZZB, whose charges are $500 \mathrm{~kg}$ (Table 1). Three of the shots (i.e., LUP, XLC and DHB) were underwater explosions. The others are multi-borehole explosions. The depths of borehole explosions are 25-30 m. 150 mobile seismographs were deployed along the profile, with a station interval of about $2.0 \mathrm{~km}$ (Figure 2). Each set of the seismographs consists of a data acquisition system (type DAS-1), which was developed by Geophysical Exploration Center, China Earthquake Administration, and a three-component short-period sensor (type CDJ-6B). The positions of shots and receivers were measured with GPS. The horizontal error of the location is less than $5 \mathrm{~m}$.

Table 1 Positions of shot points on the Chuxiong-Luoping DSS profile

\begin{tabular}{clcccrr}
\hline Name & Code & Long $/{ }^{\circ} \mathrm{E}$ & Lat $/{ }^{\circ} \mathrm{N}$ & Elevation $/ \mathrm{m}$ & \multicolumn{1}{c}{ Coordinate $/ \mathrm{km}$} \\
\hline Chuxiong & CHX & 101.4017 & 25.2036 & 1930 & 0 \\
Dahaibo & DHB & 101.6489 & 25.1761 & 1760 & 25.10 \\
Qinglongsi & QLS & 102.2993 & 25.0122 & 1874 & 300 \\
Tangchi & TCH & 103.0599 & 24.9940 & 1860 & 18.98 \\
Zhangziba & ZZB & 103.2265 & 25.0135 & 1578 & 168.86 \\
Xinglongcun & XLC & 103.5857 & 24.9958 & 1840 & 185.25 \\
Luliang & LUL & 103.6156 & 24.9638 & 1848 & 221.50 \\
Luoping & LUP & 104.3200 & 24.9571 & 1480 & 224.91 \\
\end{tabular}

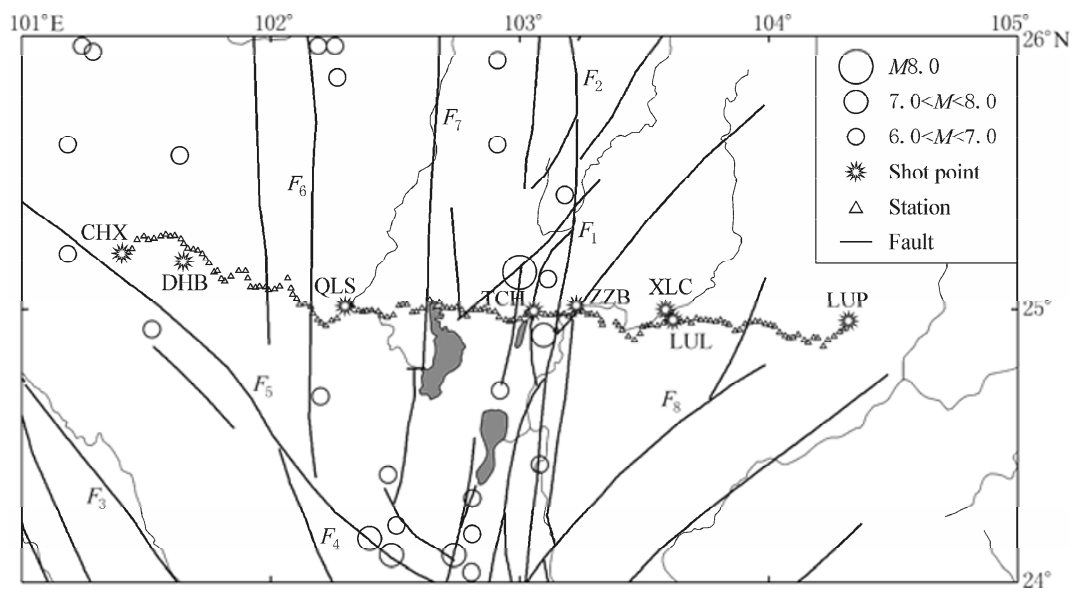

Figure 2 Locations of shot points and record stations on Chuxiong-Luoping DSS profile and epicentral distribution of strong earthquakes with $M \geq 6$. Fault marks are the same as Figure 1.

\subsection{Seismic phases on the record sections}

On the seismic record sections of all shots, the phase Pg can be recognized clearly. As the first arrival, $\mathrm{Pg}$ is the head wave or diving wave propagating in the crystalline basement. Reflected at crust-mantle boundary, phase PmP always has strong amplitude. Phase Pn, the refracted wave of uppermost mantle, can be traced on the records from some of the shots. In addition, four phases reflected on the intracrustal interfaces can be identified on the record sections. They are named $\mathrm{P}_{1}, \mathrm{P}_{2}, \mathrm{P}_{3}$ and $\mathrm{P}_{4}$ according to their arriving order. Among them, $\mathrm{P}_{3}$ has the strongest energy. In this paper, we take the reflector of phase $\mathrm{P}_{3}$ as the boundary between the upper and lower crust. Figure 3 shows the record section of the shot CHX, which is situated in the central Yunnan basin, and 160 $\mathrm{km}$ away from the west branch of XFZ. The record sec- 
tion provides the information of crustal structure to the west of XFZ. Figure 4 shows the record section of the shot $\mathrm{TCH}$, where the phases on the two sides of the shot have different behaviors. The seismic records to the west of the shot TCH reflect the structure of CDRB, while the records to the east reflect the structure of South China block. Most seismographs were installed along the main highway, so the ambient noise on the records is high, especially at the stations situated in Kunming and its nearby region. For example, seismic signals on the records at shot-receiver distance of $30-50 \mathrm{~km}$ on the west branch observation of the shot $\mathrm{TCH}$ (Figure 4) and 60-80 $\mathrm{km}$ on the east branch observation of the shot QLS (Figure 7) are almost buried by the noise.

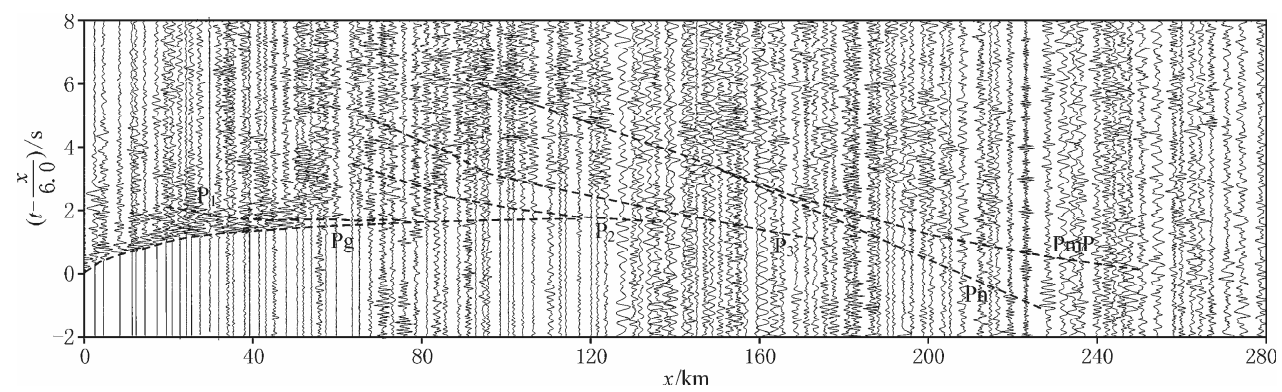

Figure 3 Trace-normalized vertical-component record section of shot CHX. The origin of distance axis is located at the position of the shot point. The record section is plotted with reduced velocity $6.0 \mathrm{~km} / \mathrm{s}$, same as below.

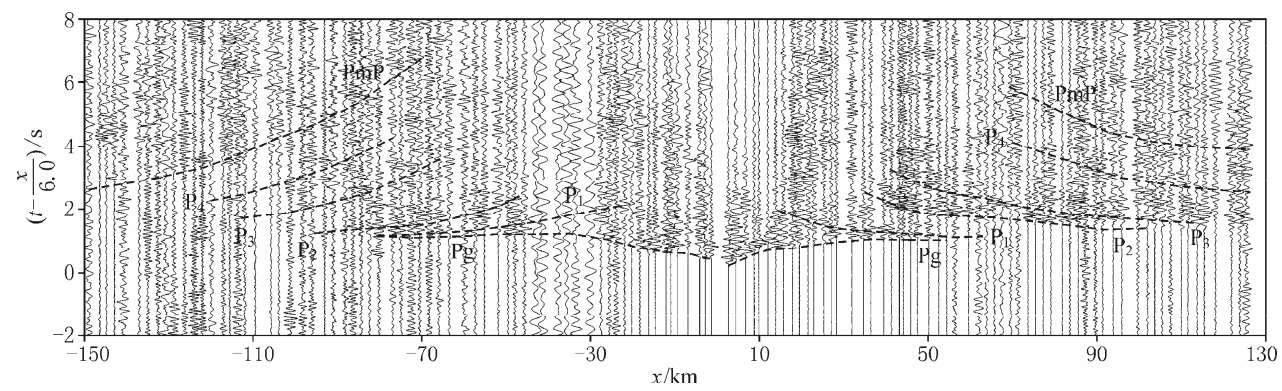

Figure 4 Trace-normalized vertical-component record section of shot TCH. The shot point is located at the intermediate zone between the west and east branches of the Xiaojiang fault zone.

Shot CHX is located at the west end of the profile, and is set to be the origin of distance coordinate axis in 2-D distance-depth section. On the record section (Figure 3), Pg has a lower apparent velocity $(5.80 \mathrm{~km} / \mathrm{s})$ at the distance within $80 \mathrm{~km} . \mathrm{P}_{1}$ is clear. $\mathrm{P}_{2}$ and $\mathrm{P}_{3}$ can also be traced. $\mathrm{PmP}$ is of stronger energy and can be traced in a distance of $80-160 \mathrm{~km}$. Pn can be traced, and the apparent velocity is estimated at $8.0 \mathrm{~km} / \mathrm{s}$.

Shot DHB is an underwater explosion and located at coordinate of $25 \mathrm{~km}$ on the west segment of the profile. The apparent velocity of phase $\mathrm{Pg}$ is as low as 5.9 $\mathrm{km} / \mathrm{s}$. $\mathrm{P}_{1}$ is clear. Both $\mathrm{P}_{2}$ and $\mathrm{P}_{3}$ can be traced. PmP can be traced continuously from $90 \mathrm{~km}$ to $160 \mathrm{~km}$. Pn can hardly be identified.

Shot QLS is located at coordinate of $93 \mathrm{~km}$ on the west segment of the profile. The record section (Figure 7) reveals that the apparent velocities of Pg on both east and west branches are low $(5.85 \mathrm{~km} / \mathrm{s}$ on the east branch and $5.90 \mathrm{~km} / \mathrm{s}$ on the west) in a distance less than $80 \mathrm{~km}$. $\mathrm{P}_{1}$ can be recognized clearly. Both $\mathrm{P}_{2}$ and $\mathrm{P}_{3}$ can be traced. $\mathrm{P}_{4}$ is relatively weak. PmP can be clearly traced eastwards from $80 \mathrm{~km}$ to $180 \mathrm{~km}$. Pn does not appear.

Shot TCH is located at coordinate of $169 \mathrm{~km}$, on the middle segment of the profile, just between the west and east branches of XFZ. On the record section (Figure 4), the apparent velocities of Pg on both west and east branches are relatively low $(5.85 \mathrm{~km} / \mathrm{s}$ on the east branch and $5.95 \mathrm{~km} / \mathrm{s}$ on the west). Both $\mathrm{P}_{2}$ and $\mathrm{P}_{3}$ can be traced. PmP can be traced in a distance of $80-160 \mathrm{~km}$. Pn does not emerge.

Shot ZZB is located at coordinate of $253 \mathrm{~km}$ on the middle segment of the profile and to the east of XFZ. The phase features exhibited on the record section are similar to those of the shot $\mathrm{TCH}$. The apparent velocity of $P g$ is $5.85 \mathrm{~km} / \mathrm{s}$. $P_{1}$ is clear. Both $P_{2}$ and $P_{3}$ can be traced. PmP can be traced from $80 \mathrm{~km}$ to $130 \mathrm{~km}$. 
Shot XLC is an underwater explosion located at coordinate of $221 \mathrm{~km}$ on the east segment of the profile. The features of phases are similar to those of the shot LUL.

Shot LUL is located at coordinate of $224 \mathrm{~km}$ on the east segment of the profile. The first arrivals within 80 $\mathrm{km}$ displayed on the record section (Figure 8) have a low apparent velocity (about $5.80 \mathrm{~km} / \mathrm{s}$ ). $\mathrm{P}_{1}$ is shown clearly. Both $\mathrm{P}_{2}$ and $\mathrm{P}_{3}$ can be traced. PmP of the east branch observation can be traced at distance of 80-160 $\mathrm{km}$. Pn can be traced, and the apparent velocity is estimated at $8.1 \mathrm{~km} / \mathrm{s}$.

Shot LUP is located at the east end of the profile. The record section shows that the apparent velocity of first arrivals within $80 \mathrm{~km}$ is low $(5.90 \mathrm{~km} / \mathrm{s}) . \mathrm{P}_{1}$ is clear. Both $\mathrm{P}_{2}$ and $\mathrm{P}_{3}$ can be traced. PmP can be traced from 80 $\mathrm{km}$ to $160 \mathrm{~km}$. Pn is not identifiable.

\section{Interpretation methods}

\subsection{Ray tracing and synthetic seismograms}

The seismic records are interpreted to obtain a 2-D crustal structure by use of the method based on the asymptotic ray theory (Cerveny et al, 1977). The ray tracing algorithm can be used to construct a 2-D velocity model with multiple interfaces, where not only the thickness of each layer is variable laterally, but also the velocity within each layer is variable laterally and vertically. On the profile, all of the recognizable seismic phases, except Pg and Pn, are reflected waves. So the average velocity of overlay medium upon the interface, at which the reflected phase is generated, can be estimated, and further, the velocity of each layer can be obtained from these average velocities. The average crustal velocity is determined from the travel times of phase PmP with the $t^{2}-\Delta^{2}$ method (Giese and Prodehl, 1976).

After determining the depths of interfaces and the average velocity of overlay medium with travel times of corresponding reflected wave, the lateral variation feature of crustal structure along the profile is revealed clearly. Firstly, travel-time modeling and synthetic seismograms calculated on 1-D velocity model for each shot is carried out to understand the structure features of crustal layers around the shot and to compose the basic data for creating a 2-D initial velocity model. Then, based upon the 2-D initial model, ray tracing method is utilized to simulate the travel times of the first arrivals and later arrivals, the 2-D synthetic seismograms calculated by the code of Cerveny and Psencik (1984) pro- vide amplitude constraint. All phases of all shots along the profile are gradually simulated from shallow to deep by modifying the 2-D velocity model. Finally, a lateral inhomogeneous crustal model is obtained. Average RMS of travel time for all phases is less than $0.05 \mathrm{~s}$, while the amplitudes of all phases in the synthetic seismograms are consistent with those in the record sections. The whole interpretation process is forward modeling, or a trial-error procedure.

\subsection{Finite difference tongraphy with the travel time of first arrival}

A finite-difference algorithm for calculating travel times of first arrivals, presented by Vidale (1988), was used here to model the Pg travel-time data. With this algorithm, the travel-times of direct wave, refracted wave, diffracted wave and head wave are calculated with a finite-difference operator based on eikonal equation. In the model, velocity values are sampled on a group of unequal interval grid nodes. The finite-difference operator, using the mean slowness over each grid cell, which is equal to the plane wave approximation on the horizontal plane of grid nodes, calculates the travel-times of first arrival wave at every grid node of the velocity model. To find the ray path, the ray tracing begins at the receiver point and goes back by the gradient of computed travel-time field. According to the reciprocity theorem, the travel time from shot to receiver can be simulated by the travel time from receiver to shot. This algorithm is much faster than the two-point ray tracing method. The computation time of this algorithm is irrespective to the velocity model, and is approximately linearly correlative with the number of grid nodes. Owing to the fast calculation and generality, the algorithm adapts to the iterating inversion procedure. The spatial resolution of the solution can be estimated by counting the number of rays in each grid cell (Wang et al, 1997). This algorithm is suitable for the velocity structure inversion of the upper crust in this paper.

\section{2-D velocity distribution along the profile}

\subsection{2-D velocity structure in the uppermost crust from travel-time tomography}

The velocity model of the uppermost crust for travel-time tomography inversion is parameterized via rectangular cells of dimension $4 \mathrm{~km}$ (horizontal) $\times 2 \mathrm{~km}$ (vertical). To maintain accuracy, a uniform 1-km spacing grid was used for travel-time calculation of the first ar- 
rivals. A total of 817 travel-times of first arrival, collected from the eight shots (Table 1) and two other shots (XRR and SNM) on the seismic exploration profile for the shallow exploration of Kunming city (Yu et al, 2008), were used in the inversion. With the finite difference algorithm developed by Hole (1992), the final velocity model was obtained after five iterations. The root mean square (RMS) of travel-time residual reduces from $0.38 \mathrm{~s}$ to $0.17 \mathrm{~s}$. The convergence of inversion is stable. The final models derived from several sets of initial parameters are basically consistent, and are in accord with the understanding from phase analysis.

The 2-D velocity model of upper crust and the 2-D ray path distribution along the profile are shown in Figure 5 as contour maps. Because the distance between shot and receiver station in the shallow seismic exploration profile is short, the penetration depths of ray paths beneath the shots XRR and SNM are shallow (3-4 km). On most sections of the Chuxiong-Luoping DSS profile, the penetration depth of ray path is as deep as $5-7 \mathrm{~km}$. Each block has more than ten rays passing throng at this depth, except for a few blocks with 5-10 rays. The inversion results, therefore, are of high reliability.

The contrast of velocity structure in the upper crust of different tectonic provinces is revealed in Figure 5. The velocity structure to the east of XFZ is relatively simple, while it is relatively complicated to the west of the fault zone. The fault zones that cross the profile exhibit themselves as velocity anomalies on the $2-D$ velocity section. The eastern branch of XFZ is located at about coordinate $175 \mathrm{~km}$, between the shot TCH and the shot ZZB, on the profile and the western branch at 160 $\mathrm{km}$. The velocity contour shows that both branches of the fault zone dip westwards and can be traced downwards to the depth of $8 \mathrm{~km}$. Between the two faults, there is a lower velocity anomaly zone. The velocity anomaly of Puduhe fault, located at Xishan of Kunming, as a small scale fault, extends downwards to only 3-4 $\mathrm{km}$. The Mile fault at the eastern part of the profile also dips westwards, but with a small velocity anomaly. The Yuanmou fault on the western segment of the profile possibly dips eastwards.
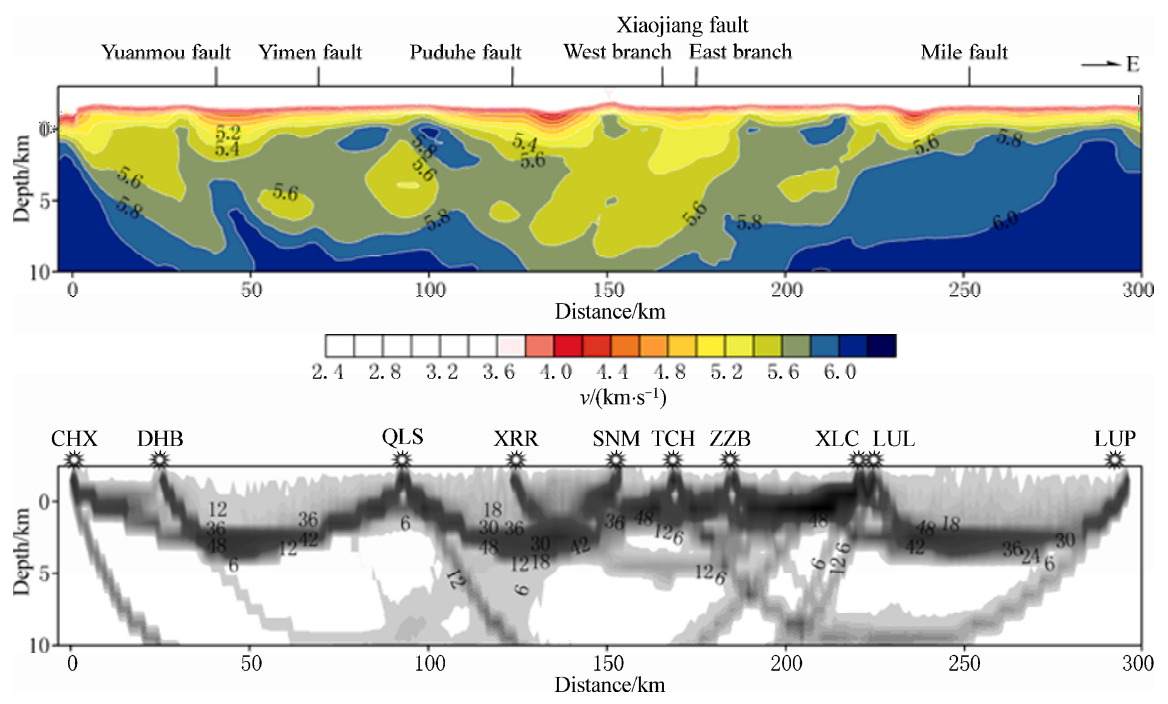

Figure 5 2-D velocity structure of the upper crust along the Chuxiong-Luoping DSS profile derived from finite-difference travel-time inversion of Pg arrivals (top) and 2-D distribution of ray density (bottom). Star denotes the shot point.

\subsection{2-D crustal velocity structure}

The initial 2-D crustal velocity model consists of five layers. In view of the energy of the reflected phases on record sections, the upper crust is divided into three layers and the lower crust is divided into two. Using the ray tracing method to model the travel time of the reflected and refracted phases, we obtained the 2-D final crustal structure (Figure 6). The origin of depth coordi- nate is set at an elevation of $1800 \mathrm{~m}$. In the 2-D velocity model, the interfaces $C_{i}$ are related to phases $\mathrm{P}_{i}(i=1,2$, $3,4)$. The depths of interfaces were determined by the arrival times of the reflection and Pn waves from all the eight shots. In the upper crust, the average interface depths corresponding to phases $\mathrm{P}_{1}, \mathrm{P}_{2}$, and $\mathrm{P}_{3}$ are $10 \mathrm{~km}$, $17 \mathrm{~km}$ and $25 \mathrm{~km}$, respectively. In the lower crust, the average interface depths corresponding to the phase $\mathrm{P}_{4}$ 
and Moho are $30 \mathrm{~km}$ and $42 \mathrm{~km}$, respectively. Phase $\mathrm{P}_{4}$ reflected from the lower crust is usually weak.

In the 2-D crustal model, the velocity distribution of the first layer, within the depth of $10 \mathrm{~km}$, was derived from the finite-difference inversion mentioned above (Figure 5). Lateral velocity variation to the west of XFZ is more intense than that to the east. The second layer is at the depth of $10-20 \mathrm{~km}$, where the lateral velocity variation is remarkable. The velocity to the east of XFZ is normal $(6.0-6.1 \mathrm{~km})$, while to the west there is a low velocity layer $(5.8-5.9 \mathrm{~km} / \mathrm{s})$. The velocity of upper crust to the east of the fault is higher than that to the west. The velocity in the lower crust, on the contrary, is slightly lower to the east of XFZ than that to the west. As a whole, the crustal average velocity to the east of XFZ $(6.32 \mathrm{~km} / \mathrm{s})$ is higher than that to the west $(6.21 \mathrm{~km} / \mathrm{s})$. Meanwhile, the crustal thicknesses on the east and west sides of XFZ are $45 \mathrm{~km}$ and $41 \mathrm{~km}$, respectively, indicating that the crust is thicker in the east than in the west.

Guided by the depth variation of intracrustal interfaces and M-discontinuity, it is inferred that the west and east branches of XFZ converge at the depth of about 25 $\mathrm{km}$, and XFZ has cut through the whole crust (Figure 6).

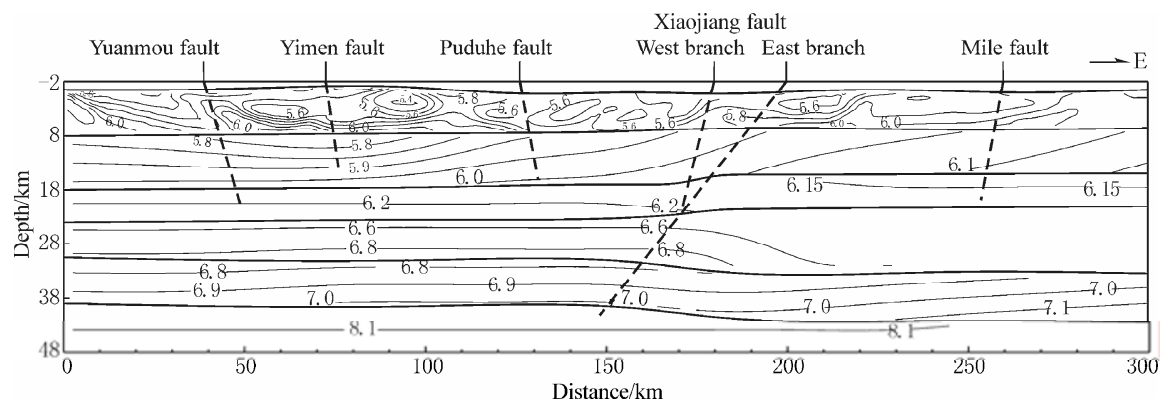

Figure 6 2-D crustal structure along the Chuxiong-Luoping DSS profile. Velocity of uppermost crust ( $-2 \mathrm{~km}$ to $8 \mathrm{~km}$ ) is determined from Pg using the finite difference inversion. Downward extension of the fault is denoted by dashed thick line.

Based upon the ray theory, the ray paths and seismograms in 2-D crustal structure were calculated. The ray paths, seismograms and record sections for the shots QLS and LUL are shown in Figures 7 and 8, respectively. The whole Chuxiong-Luoping DSS profile is situated in the Yangtze platform, but only the crust to the east of XFZ keeps the velocity structure of the stable platform, while the crust to the west of XFZ (belongs to CDRB) presents complicated crustal structure: a low velocity zone in the middle part of the upper crust and an average crustal velocity of $6.21 \mathrm{~km} / \mathrm{s}$ (lower than the global continental average velocity $6.30 \mathrm{~km} / \mathrm{s}$ ), indicating that it is a tectonically active region (Mooney and Brocher, 1987).

The Chuxiong-Luoping DSS profile intersects Eryuan-Jiangchuan profile and Simao-Malong profile in the "Dian-Shen 82" project (Kan and Lin, 1986), respectively (Figure 1). The average crustal velocities on the east and west segments of the Chuxiong-Luoping DSS profile are consistent with those derived from the record section of the shot Jiangchuan on the EryuanJiangchuan profile (Hu et al, 1986) and from the record section of the shot Malong on Simao-Malong profile
(Yan et al, 1985), respectively. Based on the SimaoMalong profile to the north of the Honghe fault, the crust is $43-45 \mathrm{~km}$ thick with an average velocity of 6.27 $\mathrm{km} / \mathrm{s}$, and the $P$ wave velocity in the uppermost mantle is $8.17 \mathrm{~km} / \mathrm{s}$. Based on the Eryuan-Jiangchuan profile, the crust is $42 \mathrm{~km}$ thick, the average $\mathrm{P}$ wave velocity is $6.19 \mathrm{~km} / \mathrm{s}$, and the velocity in the uppermost mantle is $8.05 \mathrm{~km} / \mathrm{s}$ (Kan et al, 1986; Hu et al, 1986; Kan and Lin, 1986).

\section{Discussion and conclusions}

\subsection{Deep behavior of Xiaojiang fault zone}

It can be deduced based upon features on the velocity contour map obtained by the finite-difference inversion that both east and west branches of the Xiaojiang fault zone dip westwards and extend from surface to a depth of $10 \mathrm{~km}$ or more. According to the phase analysis of record sections of eight shots along the profile, as well as the lateral velocity variation of crustal layers and the depth variation of the M-discontinuity, we infer that the west and east branches of XFZ converge at the depth of about $25 \mathrm{~km}$, and XFZ, as an important tectonicblock boundary fault zone in southwestern China, has cut 

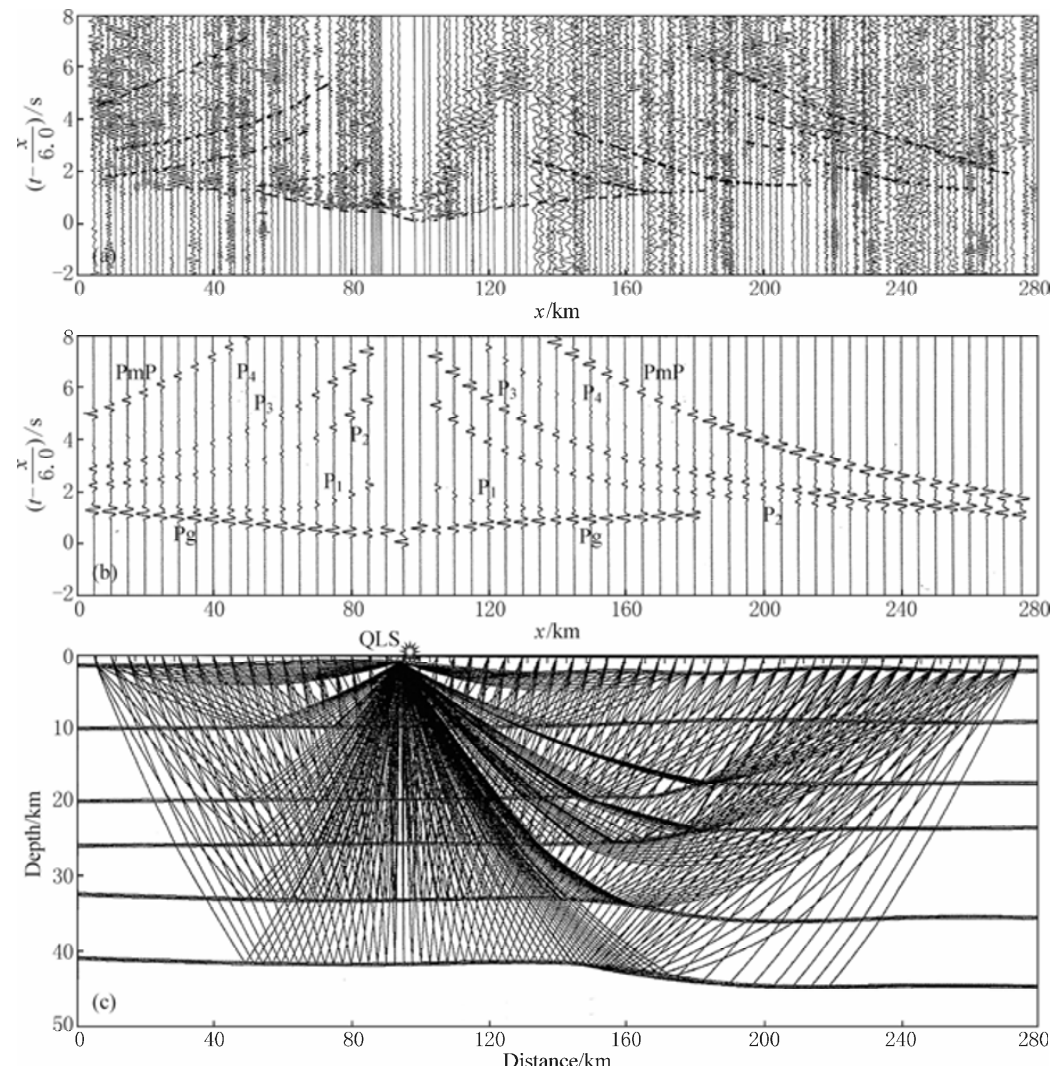

Figure 7 Comparison between record section (a) and synthetic seismograms (b) and ray paths (c) for the shot QLS.
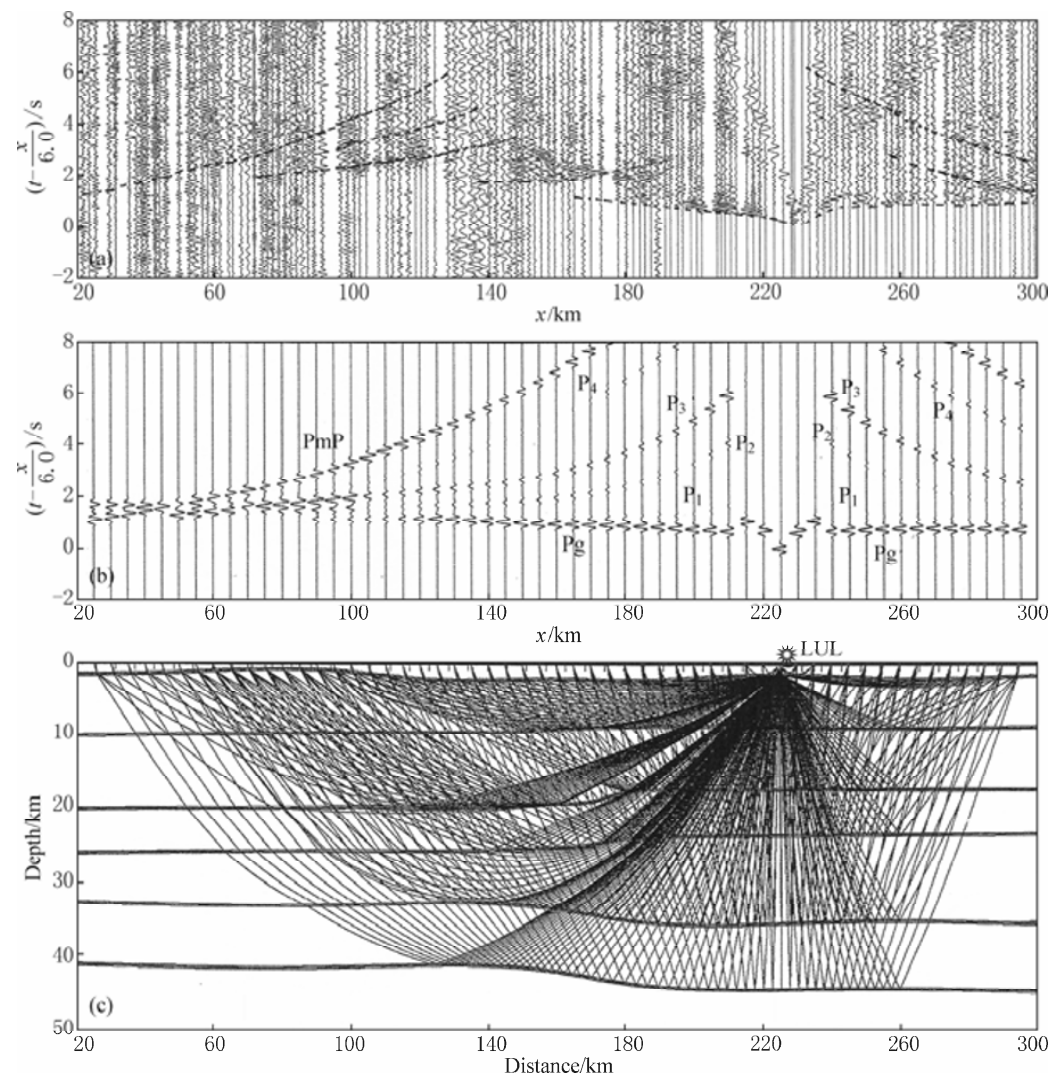

Figure 8 Comparison between record section (a) and synthetic seismograms (b) and ray paths (c) for the shot LUL. 
through the whole crust.

\subsection{Low velocity zone in the upper crust of CDRB and its tectonic implication}

Analysis of the record sections on the west segment of Chuxiong-Luoping DSS profile shows that a low velocity zone exists in the middle of the upper crust, whose structure is identical with the crust structure in the central part of CDRB, i.e., the southern part of Panzhihua-Xichang tectonic zone (Xiong et al, 1986). The crust structure of the east segment, which belongs to the South China block, is relatively simple, and there is no low velocity zone in middle of the upper crust, suggesting that it is a relatively stable tectonic block. As for the tectonic implications of the low velocity zone within the crust, it is generally believed that it may be relevant to the pore pressure and water-bearing property of the rock, or it is a weak geological layer resulting from thermal state variation of the medium. The existence of the low velocity zone is conducive to the sliding of CDRB in south-southeastward direction (Song et al, 1998).

\subsection{Earthquake risk assessment of Kunming and its nearby area}

Both the east and west branches of XFZ to the east of Kunming dip westwards with depth, while the Puduhe fault in the west of Kunming dips eastwards. The low velocity zone near the surface of Kunming basin, located between the XFZ and Puduhe fault, extends downwards for only $2-3 \mathrm{~km}$. Based on the velocity structure at shallow and intermediate depths, we found that, except the Puduhe fault zone, which is the western boundary of Kunming basin and represents a negative anomaly in velocity structure, the strike-slip fault zones of the north-south trend show no obvious relation with the velocity anomaly.

2-D crustal structure along the Chuxiong-Luoping DSS profile reveals strong lateral variation of the crustal structure, and the XFZ is the main structure boundary. To the west of XFZ, the crustal structure is quite complicated, while it is relatively simple to the east. The $P$ wave average crustal velocities to the east and west of XFZ are $6.32 \mathrm{~km} / \mathrm{s}$ and $6.21 \mathrm{~km} / \mathrm{s}$, respectively. The velocity distribution of the upper $10 \mathrm{~km}$ crust shows that there is a low velocity anomaly, which extends deeply, between the east and west branches of XFZ. The upper crust is 23-26 $\mathrm{km}$ thick and it becomes thinner from west to east, while the lower crust becomes thicker from west to east. The average crustal thicknesses to the east and west of XFZ are $41 \mathrm{~km}$ and $45 \mathrm{~km}$, respectively, indicating that the crust is thicker in the east than in the west. Based upon the depth variation of intracrustal interfaces and the M-discontinuity, it is deduced that the XFZ has cut through the crust. Although the Chuxiong-Luoping DSS profile is situated in the Yangtze platform, only the crust to the east of XFZ keeps the crustal structure feature of a stable platform, while the complex crustal structure to the west of the fault zone, which is part of CDRB, suggests where the tectonically active region should belong to (Mooney and Brocher, 1987).

Based on the features of upper-crustal velocity contours, both the east and west branches of XFZ dip westwards and extend from surface to the depth of more than $10 \mathrm{~km}$. Puduhe fault dips eastwards. The surface low velocity zone in Kunming basin extends only to a depth of $2-3 \mathrm{~km}$. From the velocity structure in shallow crust, we found that, except the Puduhe fault, which is the west boundary of Kunming basin and represents a negative anomaly in velocity structure, the strike-slip fault zones of north-south trending show no obvious relationship with the velocity variation.

Acknowledgements This paper is supported by the project "Exploration of Active Seismic Faults in Large Cities and Earthquake risk Assessment" and National Natural Science Foundation of China (Grant No. 40774037). Contribution No. is 09FE3004 of Institute of Geophysics, China Earthquake Administration.

\section{References}

Bai Z M and Wang C Y (2003). Tomographic investigation of the upper crustal structure and seismotectonic environment in Yunnan Province. Acta Seismologica Sinica 16(2): 127-139.

Bai Z M and Wang C Y (2004). Tomographic research of Zhefang-Binchuan and Menglian-Malong wide-angle seismic profiles in Yunnan Province. Chinese J Geophys 47(2): 257-267 (in Chinese with English abstract).

Bureau of Geology and Mineral Resources of Yunnan Province (1990). Regional Geological Annals of Yunnan Province. Geological Publishing House, Beijing, 659-727 (in Chinese with brief text in English).

Cerveny V, Molotkov I A and Psencik I (1977). Ray Method in Seismology. Univerzita Karlova, Prague, 13-216.

Cerveny V and Psencik I (1984). SEIS83N-Numerical modeling of seismic wavefield in 2-D laterally varying layered structures by the ray method. In: Engdahl E R ed. Documentation of Earthquake Algorithm, World Data Center (A) for Solid Earth Geophysics. Rep. SE-35, Boulder, Colo. 36-40.

Chen P S, Liu F T, Li Q and Qin J (1990). Lateral heterogeneity of the velocity structure in Yunnan. Science in China (Series D) 4: 431-438 (in Chinese).

Giese P and Prodehl C (1976). Problems of evaluation of seismic-refraction data for crustal and upper-mantle studies. In: Giese P, Prodehl C and Stein A eds. Explosion Seismology in Central Europe. Springer, Heidelberg, 146-147.

Hole J A (1992). Nonlinear high-resolution three-dimensional seismic travel time tomography. $J$ Geophys Res 97: 6 553-6 562.

Hu H X, Lu H X and Wang C Y (1986). Explosion investigation of the crustal structure in western Yunnan Province. Acta Geophysics Sinica 29: 133-144 (in Chinese with English abstract). 
Kan R and Han Y (1992). Direction of the Geoscience Transect From Zhefang to Malong, Yunnan. Geological Publishing House, Beijing, 1-30 (in Chinese).

Kan R, Hu H, Zeng R, Mooney W and McEvilly T V (1986). Crustal structure of Yunnan Province, People's Republic of China, from seismic refraction profiles. Science 234: 433-437.

Kan R and Lin Z (1986). Preliminary study on crustal and upper mantle structure in Yunnan. Earthq Res in China 2(4): 50-61 (in Chinese).

Kan R, Zhang S C and Yan F T (1977). Modern tectonic stress field in southwestern China. Acta Geophysica Sinica 20(2): 96-110 (in Chinese).

Liu J H, Liu F T and Wu H (1989). Three dimensional velocity images of the crust and upper mantle beneath North-South Zone in China. Chinese J Geophys 32: 143-151 (in Chinese).

Ma X Y (1989). Lithospheric Dynamics Atlas of China. China Cartograph Publishing House, Beijing, 51 (in Chinese with English abstract).

Mooney W D and Brocher T M (1987). Coincident seismic reflection/refraction studies of the continental lithosphere: A global review. Rev Geophys 25: 723-742.

Song F M, Wang Y P, Yi W X, Cao Z Q, Shen X H and Shen J (1998). Xiaojiang Active Fault Zone. Seismological Press, Beijing, 1-52 (in Chinese).

Vidale J E (1988). Finite-difference traveltime calculation. Bull Seism Soc Amer 78: 2 062-2 076

Wang C Y, Chan W W and Mooney W D (2003). 3-D velocity structure of crust and upper mantle in southwestern China and its tectonic implications. $J$
Geophys Res 108(B9): 2 442, doi:10.1029/2002JB001973.

Wang C Y, Wang X L and Yan Q Z (1994). Three-dimensional velocity structure beneath the Kunming Telemetered Seismic Network. Acta Seismologica Sinica 7(2): 217-226.

Wang C Y, Zhang X K, Song J L and Ding Z F (1997). Finite-difference tomography of upper-crustal velocity structure in Dabieshan orogenic belt Acta Geophysica Sinica 40: 495-502 (in Chinese with English abstract).

Xie Y S (1958). Earthquake activity and surface fault in the central and eastern Yunnan. Acta Geophysica Sinica 7(1): 31-40 (in Chinese).

Xiong S B, Teng J W and Yin Z X (1986). Explosive seismological research on the structure of crust and upper mantle in the Panxi tectonic belt. Acta Geophysica Sinica 29: 235-244 (in Chinese with English abstract).

Yan Q Z, Zhang G Q, Kan R J and Hu H X (1985). The crustal structure of Simao to Malong profile, Yunnan province, China. J Seism Res 8(2): 249-280.

Yu G X, Lou H, Wang C Y, Fu L Y, Zhang J G, Qin J Z, Yang R H and Li H O (2008). Shallow velocity structure and hidden faults of Kunming city region. Acta Seismologica Sinica 21(5): 502-508.

Zhang Z J, Bai Z M and Wang C Y (2005) Crustal structure of Gondwana- and Yangtze-typed blocks: An example by wide-angle seismic profile from Menglian to Malong in western Yunnan. Science in China (Series D) 48(11): $1828-1836$

Zhou Z H, Xiang C Y and Yang K J (2001). Petrological structure of the crust and upper mantle in Yunnan, China. Seismol Geol 23(1): 69-78 (in Chinese with English abstract). 